\title{
PROPOSTA PARA A IMPLANTAÇÃO DO MÉTODO CUSTOMER SUCCESS EM INSTITUIÇÕES DE ENSINO SUPERIOR
}

Cindy Bernardes CAMPOS ${ }^{1}$

Luiz Antônio de Carvalho GODINHO ${ }^{1}$

Maria Eugênia Monteiro CASTANHEIRA ${ }^{3}$

\begin{abstract}
${ }^{1}$ Graduada do Curso de Administração do Centro Universitário Newton Paiva, cindybernardes@gmail.com ${ }^{2}$ Doutor em Administração, professor do Centro Universitário Newton Paiva, luiz.godinho@newtonpaiva.br ${ }^{3}$ Mestre em Administração, professora do Centro Universitário Newton Paiva, maria.monteiro@newtonpaiva.br
\end{abstract}

Recebido em: 10/11/2017 - Aprovado em: 10/12/2017 - Disponibilizado em: 30/12/2017

\begin{abstract}
RESUMO
Observa-se uma grande quantidade de alunos insatisfeitos com o atendimento prestado pela Instituição de Ensino Superior (IES) e que desistem dos cursos, gerando um alto churn (taxa de cancelamento) e outras preocupações para gestão de desempenho da IES. A nova tendência do Marketing 4.0, focada em proporcionar a melhor experiência ao cliente com ferramentas digitais e o método Customer Success (CS), em português Sucesso do cliente, focado em se antecipar em relação aos problemas e surpreender o cliente proporcionando o seu verdadeiro sucesso, podem reverter essa realidade, melhorar o desempenho da IES e atrair novos alunos. Pretende-se neste estudo levantar as principais queixas dos alunos em relação ao atendimento prestado e apresentar o método Customer Success como uma solução para a IES diminuir o churn, elevar a satisfação dos seus alunos e entregar o seu sucesso, fazendo-o indicar a IES como uma referência para a comunidade em que está inserido.
\end{abstract}

Palavras-Chave: Customer Success. Sucesso do Cliente. Gestão. Retenção. Atendimento.

\begin{abstract}
There is a large number of students unsatisfied with the care provided by the Higher Education Institution (HEI) which leads them to drop out of the courses, generating a high churn (cancellation fee) and other concerns for HEI performance management. The new trend of Marketing 4.0, focused on providing the best customer experience with digital tools and the Customer Success (CS) method. Customer success, focused on anticipating problems and surprising the customer by delivering their true success, can reverse this reality, improve the performance of HEI and attract new students. The aim of this study is to raise the students' main complaints regarding the service provided and to present the Customer Success method as a solution for HEI to reduce churn, to increase the satisfaction of its students and to deliver its success, making them indicate the HEI as a reference for the community in which it is inserted.
\end{abstract}

Keywords: Customer Success. Sucesso do Cliente. Management.Retention.Attendance. 


\section{INTRODUÇÃO}

Observa-se uma grande quantidade de alunos insatisfeitos por algum motivo e que desistem dos cursos oferecidos pela IES gerando um churn elevado. A nova tendência Customer Success baseada no Marketing 4.0 pode reverter essa realidade. Quais são as vantagens da implantação do método de Customer Success em IES?

Pretende-se neste estudo apresentar o conjunto de benefícios da implantação do método Customer Success em IES, que pode diminuir o churn e elevar a satisfação do aluno. Pretende-se também levantar as principais razões que levam os alunos a desistirem dos cursos, analisar como a IES lida com a gestão das retenções e propor uma solução para melhoria do desempenho da IES, demonstrando a importância de sair do já conhecido atendimento ao cliente para buscar oferecer o sucesso desse cliente.

Acredita-se que este estudo pode contribuir para a gestão de IES que procura reverter o desempenho ruim pela elevada taxa de cancelamento e também elevar a satisfação do aluno, engaja-lo e leva-lo a indicar e defender a IES para a comunidade em que está inserido.

Quanto a metodologia, a classificação da pesquisa quanto aos fins é descritiva e aplicada e quanto aos meios é bibliográfica e de campo.

\section{REFERENCIAL TEÓRICO}

Segundo Kotler (2017) no mercado atual muito se tem ouvido falar das mudanças comportamentais dos clientes e das empresas frente a evolução do Marketing. Várias ferramentas chegaram para ajudar as empresas a se adaptarem a essas mudanças e uma dessas ferramentas é método Customer Success.

Para Muphy (2016) um método para diminuir o churn e melhorar a qualidade do atendimento ao cliente, superando as expectativas dos clientes e fazendo o relacionamento empresa-cliente ser mais pessoal. Com o intuito de entender a revolução do Marketing 4.0, a ferramenta Customer Success e índice churn, serão tratados a seguir os seus conceitos e suas características.

\section{O comportamento do cliente no}

\section{Marketing 4.0}

Para Rechiche (2015) o Marketing 1.0 centrado no produto mudou para Marketing 2.0 centrado no consumidor, que evoluiu para Marketing 3.0 centrado no ser humano, ou seja, o consumidor foi reconhecido como mais do que um simples comprador. Ele possui preocupações coletivas, ambientais e aspira por uma sociedade melhor, sustentável. Esta fase pode ser chamada "Era do Valor".

Segundo Barbosa (2010) o marketing 4.0 éfortemente baseado em sentimentos e valores humanos, transformações sociais e 
interatividade na rede, onde qualquer um pode fazer e ser mídia e todos têm o poder de persuasão.

Para Peçanha (2017) é necessário lembrar que, quando alguém procura alguma informação, raramente inicia por "quero comprar"mas sim por "tenho um problema".

Segundo Rez (2016) as pessoas estão interessadas nos atributos, nos valores agregados do produto ou serviço e principalmente interessadas na experiência, em entender como o produto ou serviço pode leva-las aonde desejam, ao seu sucesso, por isso avaliam vários fatores e opiniões de outros consumidores antes de tomar sua decisão de compra.

Para Rez (2016) os consumidores se tornaram indivíduos exigentes, bastante criteriosos e com acesso ilimitado a informações sobre qualquer assunto. Este perfil é o novo consumidor online, que quando fica satisfeito com sua experiência, torna-se divulgador da marca, indicando e defendendo a marca para amigos e familiares. Para ele o contrário também é verdade. Em caso de uma experiência decepcionante o consumidor terá o mesmo poder de influência expondo suas insatisfações a comunidade em que está inserido, podendo negativar a imagem da marca.

Segundo Kotler (2017) a mudança do marketing 3.0 para o marketing 4.0 é a transformação de processo de serviço ao cliente para o atendimento colaborativo ao cliente. Em vez de apenas atender e servir o cliente, a empresa mostra uma preocupação genuína com o cliente ao ouvir, responder e acompanha-lo nas condições determinadas pelo cliente e pela empresa.

Gabriel (2010) afirma que o consumidor passa a estar no centro das atenções de forma ativa entre as marcas. A marca passa a ser responsável pelo sucesso da experiência do cliente.

Para Kotler (2017) o foco do marketing tradicional era iniciar a interação com os clientes ao passo que o marketing digital procura promover resultados para esses clientes.

Kotler (2017) também acredita que as empresas deveriam procurar sempre melhorar os seus serviços ou produtos e inovar na experiência do cliente, pois o lado humano do consumidor foi revelado e valorizado e é hora das marcas também revelarem o seu lado humano e valorizar a autenticidade, demonstrando atributos capazes de atrair consumidores e desenvolver conexões de pessoa a pessoa.

\section{Customer Success: conceito e características}

Segundo Agendor e Edools (2016) Customer Success é um método novo que tem como objetivo fundamental garantir aos clientes uma excelente experiência com seus produtos ou serviços. 
O grande mestre do método Customer Success, Murphy (2016), diz que o método nasceu para fazer a gestão de Sucesso do cliente que é o arranjo proativo da jornada do cliente em busca do seu, sempre em evolução, resultado esperado. Em resumo, Sucesso do cliente é importante porque ajuda a empresa a fazer exatamente o que existe para fazer.É ovalor intangível que leva uma pessoa a fazer negócios com sua marca.

A missão da sua empresa é fazer com que seus clientes consigam algo. A verdade é que ninguém compra, assina, aluga ou troca coisa nenhuma pelo seu produto, marca ou serviço. O consumidor te dá tempo e dinheiro porque ele quer alguma coisa e o seu produto, marca ou serviço se manifestam ali como uma boa maneira de chegar no que ele quer. As pessoas não compram o que você vende. Elas compram progresso. (ROCKCONTENT, 2017, p. 7)

Para Agendor e Edools (2016) assim como todas as fases do processo de vendas, o pós-vendas merece muita atenção e precisa ser bem trabalhado. Nessa etapa decisiva para a retenção, o cliente deve continuar a ser o centro das atenções.

Há empresas que buscam atuar com foco em melhorias e novas alternativas para melhor atender os clientes de sua carteira, trabalhando para que se sintam valorizados e mais satisfeitos. $\mathrm{O}$ problema é que grande parte do mercado ignora críticas, não investe em avanços e até intensifica o processo de vendas (investindo na captação de novos clientes), passando a cultivar um público insatisfeito e inseguro. É aí que conceito de Customer Success ou Sucesso do cliente surge para mudar as regras do jogo por meio de um maior foco nos atuais clientes, como forma de retê-los e engajá-los a continuarem (ou voltarem) a consumir produtos ou serviços. (AGENDOR e EDOOLS, 2016, p. 4)

Murphy (2016) complementa que o trabalho de um time de Customer Success vai muito além do simples atendimento ao cliente ou qualquer tipo de suporte. A área de Customer Success atua de maneira proativa, ou seja, ela não espera o cliente ter alguma dúvida ou problema. Pelo contrário, a equipe atua ativamente para certificar-se de que os clientes estão alcançando os melhores resultados e entendendo a lógica daquele serviço ou produto.

A figura 1 demonstra a diferença entre o métodoCustomer Success e os serviços tradicionais de pós-venda, atendimento ao cliente e SAC.

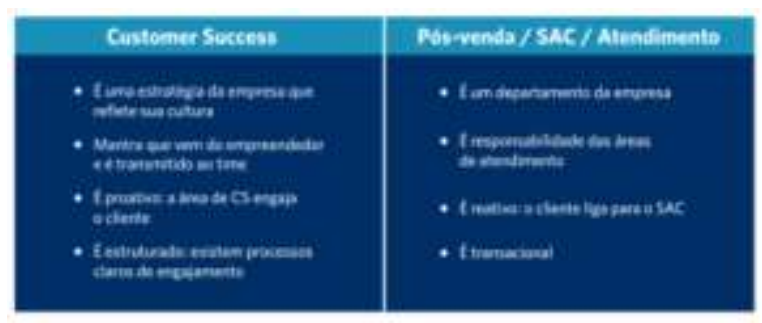

Figura 1. Fonte: https://endeavor.org.br/mentoriaonline-customer-success/

Para Murphy(2016) a estratégia, por meio da transparência e proatividade da 
equipe de Customer Success, resultam em retenção e fidelização dos clientes, ou seja, aumenta o lifetime value (valor do tempo de vida do cliente na instituição).

Cada vez mais, notamos o mercado preocupado em reter clientes e as empresas já começam a enxergar que investir em uma estratégia bem planejada de Customer Success, tendo como objetivos os resultados que seus clientes almejam e a experiência excepcional que eles têm com a marca, é essencial para conseguir que eles voltem a comprar no próximo mês ou em uma próxima oportunidade.(AGENDOR E EDOOLS, 2016, p. 10)

Murphy (2016) também afirma que o profissional que deseja trabalhar em CS precisa ter paixão em atender, lidar com o público e solucionar problemas, ter também curiosidade e resiliência, habilidade de comunicação oral e escrita, ser um bom ouvinte e ter empatia. Aliadas a tecnologia e ao CRM da IES todas essas habilidades da equipe de CS construirão um relacionamento de confiança com o aluno, podendo reverter o alto índice de churn e melhorar o índice de satisfação da IES pelos alunos.

\section{Porque uma IES deve investir em Customer Success?}

Os principais motivos para uma IES, que oferece cursos presenciais ou on-line, investir em Customer Success são:
Diminuição dos índices de churn: diz respeito à alta rotatividade de alunos por diferentes razões. No geral, a maioria das instituições de ensino não busca entender o real motivo de um cancelamento de matrícula.

Por isso, elas são pegas de surpresa justamente por não acompanharem a trajetória do aluno durante o período em que o mesmo está matriculado. Isso se justifica por não haver dentro da instituição um profissional que tenha como objetivo guiar e servir o aluno em todas as suas dúvidas e dificuldades para, de fato, maximizar seu potencial por meio de apoio e acompanhamento prático. A atuação de um profissional de Customer Success é fundamental nesse sentido; podemos dizer que o churn é seu inimigo número um, já que perder um aluno é o principal indicador do fracasso desse profissional. Logo, é preciso ter certeza de que seu CS fará de tudo para conquistar, engajar e motivar cada aluno para que sua experiência seja a melhor possível. (...) se um aluno recebe todos os insumos necessários por parte de um profissional preparado e qualificado para que sua experiência seja produtiva e positiva, as chances de abandonar $o$ curso no meio são muito pequenas. (AGENDOR E EDOOLS, 2016, p. 11)

Melhoria do atendimento a clientes: Para Agendor e Edools (2016) o atendimento ao cliente nos dias atuais tem sido muito valorizado e oferecer inovações e melhorias pode significar alunos mais engajados e motivados com o curso e a marca da IES. 
Com um profissional qualificado destinado a atender os alunos, estes acabam sendo impactados muito positivamente, refletindo na melhora da percepção de qualidade e aproveitamento do curso como um todo.

Possibilidades de indicações: Oferecer um atendimento personalizado e com foco na resolução de problemas é uma das principais vantagens que se pode oferecer aos alunos para fazer com que a IES gere resultados surpreendentes.

Esse atendimento diferenciado, tendo o aluno como foco de qualquer perspectiva, faz com que exista uma propensão muito maior de indicações a novas redes de contatos. Agora imagine se cada aluno que tenha uma boa experiência com sua marca convide conhecidos para fazer algum curso em sua instituição. A situação fica ainda melhor se você conseguir escalar essas inscrições. (AGENDOR E EDOOLS, 2016, p 14)

\section{METODOLOGIA}

Para a classificação da pesquisa, tomase como base a taxionomia apresentada por Vergara (2016) que a qualifica em relação a dois aspectos: quanto aos fins e quanto aos meios. Quanto aos fins a pesquisa é descritiva e aplicada por demonstrar os motivos das desistências dos alunos e por sugerir uma proposta de solução para reverter a realidade.
Quanto aos meios, a pesquisa é bibliográfica e de campo, pois a fundamentação se dá por pesquisa em livros, e-books, artigos científicos, sites, palestras on-line, vídeos e por se utilizar da observação quanto ao funcionamento cotidiano da IES para compor o estudo. A observação pessoal da autora contemplou acompanhamento presencial dos atendimentos telefônicos, atendimento por chat, atendimento por e-mail, atendimento por whatsapp e atendimento presencial pelos profissionais da CRA. Não foi permitido o uso de questionários ou entrevistas.

\section{RESULTADOS E DISCUSSÃO}

Após a observação da rotina de trabalho da CRA da IES estudada, foi possível levantar pontos críticos no que se refere a demanda dos alunos, que passam por simples solicitações a problemas de diferentes escalas dos alunos, conforme relatado a seguir.

Os alunos enfrentam problemas e possuem dúvidas no uso das plataformas online oferecidas pela IES usada para acessar materiais, planos de ensino e estudos, realizar provas, postar trabalhos, consultar avisos, cronogramas e conferir notas e faltas. Enfrentam problemas nos processos de rematrículas, inscrições em disciplinas isoladas, consultas ao histórico acadêmico, financeiro e grade curricular, emissão de 
declarações para diversos fins, remarcação de provas, inscrição para eventos como feiras, congressos, seminários, workshops, reuniões e palestras, assistir ou aplicar monitorias das disciplinas do curso, enfrentam problemas ao protocolar os documentos comprobatórios das atividades complementares obrigatórias exigidas pelo curso e também enfrentam problemas para encontrar instruções para a colação de grau. Muitas vezes o sistema oferecido para controlar os pedidos e solicitações dos alunos falha e há morosidade na resolução por parte da IES.

Além disso, os alunos enfrentam dificuldades nos prazos de análise de documentações diversas, relatórios e trabalhos, por parte da IES. Deparamsetambém com problemas de lançamentos incorretos de notas, faltas e horas referentes às atividades complementares obrigatórias, emissão de segunda via de boletos, emissão de carteira estudantil e na concessão dos empréstimos estudantis como FIES, PROUNI e PRAVALER.

Grande parte destes pontos observados chegaram na CRA da IES em tom reclamativo por parte dos alunos, que alegaram estar tentando resolver suas questões pela segunda, terceira vez ou até por mais vezes. Estes alunos afirmaram que os atendentes presenciais, virtuais ou por telefone não sabem tirar suas dúvidas e não conseguem indicar alguém que possa atender de forma ágil a sua necessidade, disseram ser muito difícil conseguir contato direto com o responsável por determinadas áreas internas da IES e que ficaram aguardando a solução das suas dúvidas e necessidades por protocolos abertos com prazo de resposta de sete a quinze dias, que as vezes se esgotam sem resposta. Alguns alunos afirmaram que o tratamento dado a eles pela IES e pela CRA fez com que perdessem a credibilidade e a confiança que eles construíram, de alguma forma, pela IES.

A IES estudada não permitiu a apuração e analise quantitativa de dados por isso não foi possível levantar números ou estatísticas sobre índices de desistências e insatisfação dos alunos.mas garantiu estar preocupada com o alto churn e deseja agir em prol de solução.

Durante o período de observação os profissionais da CRA por vezes se sentiram perdidos por falta de comunicação interna da IES e não souberam como tratar determinado problema, adiando-o de alguma forma, para ter tempo de buscar a resposta adequada a situação. Sentiram-se irritados e desmotivados por não conseguir atender a expectativa dos alunos rapidamente e por receber reclamações diretas sem ter autonomia para agir.

Após as observações foi possível observar características na gestão atual da IES que arremete ao marketing 2.0 e 3.0, focado na espera da iniciativa do cliente em tomar decisões ou dar feedback e por isso entendese que a proposta de solução sugerida poderá 
ajudar a IES a avançar para o marketing 4.0, se destacando da concorrência, melhorando e inovando a qualidade da prestação de serviço de ensino, agindo de maneira preventiva e proativa, surpreendente e eficaz, buscando o sucesso do aluno.

\section{CONCLUSÃO}

Diante do cenário observado e das informações colhidas é possível propor a implantação do método Customer Success na atual Central de Relacionamento com o Aluno, para solucionar o grande volume de demandas não atendidas, buscando sempre trabalhar de maneira prévia paraelevar o grau de satisfação dos alunos de forma que indiquem a IES para a comunidade em que está inserido e se torne naturalmente um advogado da marca. Além disso acredita-se, que com a implantação da técnica, o clima organizacional e a motivação dos profissionais da CRA podem melhorar.

Portanto, este estudo sugere uma proposta de solução para a melhoria de desempenho da CRA da IES através do método que busca o Sucesso do Cliente. Sugere-se a formação do time de CS de 05 pessoas, aproveitando os talentos da CRA ou contratando novos talentos. Cada um do time ficará responsável pela gestão de 400 alunos, a fim de garantir a cobertura completa dos serviços oferecidos pelo time de CS com igual qualidade e atenção aos atuais dois mil alunos ativos da IES.
Com o aumento do número de alunos da IES a gestão da IES deverá contratar mais profissionais para o time de CS.

Sugere-se também a elaboração e aplicação de uma pesquisa de satisfação aos alunos para que sejam levantadas todas as objeções possíveis em relação ao atendimento atual oferecido pela IES a fim de analisa-las detalhadamente. Com base no feedback da pesquisa sugere-se o desenvolvimento de um plano de ação eficazpara solucionar os pontos críticos da pesquisa e definir a atuação da equipe de CS em busca da reversão da situação e superação de expectativas. A criação do plano de ação deve envolvero time de CS, a gestão da CRA, da IES e demais áreas necessárias.

Sugere-se também a realização de constantes treinamentos ao time de CS e dar ao time a autonomia necessária para atuar. $\mathrm{O}$ direcionamento pela gestão da CRA é imprescindível, sugere-se então acompanhar os resultados e promover reuniões frequentes com todo o time para troca de experiências, possíveis ajustes de atuação e também a comemoração de resultados e reconhecimento do trabalho que fizeram.

Considerando a adesão da IES à proposta sugerida neste estudo, os benefícios da implantação do método Customer Success seriam o aumento da satisfação do aluno, afinal a equipe trabalhará em prol de solução eficaz e rápida para superar as expectativas do aluno; a diminuição do churn, pois os alunos 
satisfeitos não desejam mudar de instituição e por fim o aumento de indicações de novos alunos pelos alunos atuais pelo impacto positivo na divulgação da marca através da experiência dos alunos. Fica claro que a IES pode estagnar se não evoluir na perspectiva de superação de expectativas dos seus alunos, podendo sofrer desvantagem competitiva e diminuição da fatia de participação no mercado (marketshare).

\section{REFERÊNCIAS}

\section{AGENDOR \& EDOOLS, Customer}

Successem EAD. 2016. Disponível em: <https://goo.gl/7BqWSo> Acesso em 10. Out. 2017.

BARBOSA, Alan. Marketing 4.0. Disponível em: <https://goo.gl/xb9imz> Acesso em 05. Out. 2017.

GABRIEL, Martha. Marketing na era digital. Conceitos, plataformas e estratégias. São Paulo: Editora Novatec, 2010, 424p.

KOTLER, Philip; KARTAJAYA, Hermawan; SETIAWAN, Iwan.Marketing 4.0: do Tradicional ao Digital. Rio de Janeiro: Editora Sextante, 2017, 201p.

MURPHY, Lincoln; STEINMAN, Dan; MEHTA, Nick. Customer Success: How Innovative Companies Are Reducing Churn and Growing Recurring Revenue. New Jersey: Editora Wiley, 2016, 238p.

PEÇANHA, Vitor. Obrigado pelo marketing. Um guia completo de como encantar pessoas e gerar negócios utilizando o marketing de conteúdo. São Paulo: Editora Benvirá, 2017, 238p.

RECHICHE, Marcelo. Marketing 1.0, 2.0, 3.0. Qual a diferença? Disponível em:
<https://goo.gl/pprAaW> Acesso em 05. Out. 2017.

REZ, Rafael. Marketing de Conteúdo. A moeda do século XXI. São Paulo: Editora DVS, 2016, 379p.

ROCKCONTENT. Tudo O Que Você Precisa Saber Sobre Customer Success. 2016.

VERGARA, Sylvia Constant. Projetos e Relatórios de Pesquisa em Administração. São Paulo: Editora Atlas, 2016, 94p. 